\title{
Causes of ambiguity aversion: Known versus unknown preferences
}

\author{
Stefan T. Trautmann • Ferdinand M. Vieider • \\ Peter P. Wakker
}

Published online: 3 May 2008

(C) The Author(s) 2008

\begin{abstract}
Ambiguity aversion appears to have subtle psychological causes. Curley, Yates, and Abrams found that the fear of negative evaluation by others (FNE) increases ambiguity aversion. This paper introduces a design in which preferences can be private information of individuals, so that FNE can be avoided entirely. Thus, we can completely control for FNE and other social factors, and can determine exactly to what extent ambiguity aversion is driven by such social factors. In our experiment ambiguity aversion, while appearing as commonly found in the presence of FNE, disappears entirely if FNE is eliminated. Implications are discussed.
\end{abstract}

Keywords Ambiguity aversion $\cdot$ Fear of negative evaluation $\cdot$ Home-bias

JEL classification C91, D81, Z13

In decision under uncertainty people have been found to prefer options involving clear probabilities (risk) to options involving vague probabilities (ambiguity), even if normative theory (Savage 1954) implies indifference. This phenomenon is called ambiguity aversion (Ellsberg 1961). Ambiguity aversion has been shown to be economically relevant and to persist in experimental market settings (Gilboa 2004; Sarin and Weber 1993) and among business owners and managers familiar with decisions under uncertainty (Chesson and Viscusi 2003). People are often willing to spend significant amounts of money to avoid ambiguous processes in favor of normatively equivalent risky processes (Becker and Brownson 1964; Chow and Sarin 2001; Keren and Gerritsen 1999).

Curley et al. (1986) found that increasing the number of people watching a decision enhanced ambiguity aversion, and enhanced it more than other factors that they manipulated. The relevance of evaluations by others is supported by Fox and

S. T. Trautmann • F. M. Vieider • P. P. Wakker $(\square)$

Econometric Institute, Erasmus University, P.O. Box 1738, Rotterdam 3000, The Netherlands

e-mail: Wakker@few.eur.nl

URL: http://www.few.eur.nl/few/people/wakker/ 
Tversky (1998), Fox and Weber (2002), and Heath and Tversky (1991), showing that ambiguity aversion increases with the perception that others are more competent and more knowledgeable. If people choose an ambiguous option and receive a bad outcome, then they fear criticisms by others. Such criticisms are easier to counter after a risky choice, when a bad outcome is more easily explained as bad luck, than after an ambiguous choice. This explains the enhanced ambiguity aversion. We will call such social effects fear of negative evaluation (FNE), borrowing a term from psychology (Watson and Friend 1969). A detailed review of the literature on FNE for ambiguity will be presented in Section 1 .

The studies of ambiguity aversion available in the literature so far could not determine the extent to which ambiguity aversion can exist beyond FNE. It was always clear what the preferred outcomes were and this information was public for the experimenter and others, so that subjects could always be criticized if they received a bad outcome. We introduce a design where preferences between outcomes are the subjects' private information that cannot be known to the experimenter or to other people unless the subjects explicitly reveal it. Thus, we can completely control the presence or absence of FNE, and we can exactly determine the effect of the corresponding social factors on ambiguity aversion.

In our main experiment, the stimuli are two DVDs that, on average, are equally popular but between which most individuals have strong preferences. These preferences are unknown to others, in particular to the experimenter. Subjects choose between a risky prospect and an ambiguous prospect to win one of the two DVDs. With preferences between the DVDs unobservable, the decision maker cannot be judged negatively by the experimenter or others because only the decision maker knows what the winning and what the losing outcome is. Remarkably, eliminating the possibility of evaluation by others makes ambiguity aversion disappear entirely in our experiment. Introducing the possibility of evaluation by letting subjects announce their preference between the DVDs before they make their choice is sufficient to make ambiguity aversion reemerge as strongly as is commonly found. Thus, our finding adds to the aforementioned studies showing how important social factors are for ambiguity aversion.

A research question resulting from our study is to what extent ambiguity aversion can exist at all in the absence of FNE, that is, to what extent it is at all a phenomenon of individual decision making. Most of the theories popular today use individual decision models to analyze ambiguity attitudes.

To provide psychological background for our finding, we did another experiment with the classical Ellsberg urn and with traditional monetary outcomes, where we additionally measured subjects' sensitivity to FNE using Leary's (1983) scale. We indeed found a positive correlation between this scale and ambiguity aversion, confirming our interpretations.

Empirically, many economic phenomena deviating from traditional rational choice theory have been attributed to ambiguity aversion (Camerer and Weber 1992; Gilboa 2004; Mukerji and Tallon 2001). A famous example is the home bias in consumption and financial investment (French and Poterba 1991). Implications of our findings regarding FNE for such phenomena will be discussed in Section 5.

This paper proceeds as follows. The next section discusses the FNE hypothesis and its literature. Section 2 presents a replication of the Curley et al. (1986) result 黑 Springer 
and discusses the role of hypothetical choice for ambiguity. The main experiment and a discussion of its results are in Section 3. Section 4 considers the role of FNE as a personality trait for ambiguity aversion. Section 5 discusses theoretical and empirical implications. Finally, Section 6 concludes.

\section{Literature on the fear of negative evaluation}

A central point in the explanation of ambiguity aversion concerns the perceived informational content of the outcome generating process. People shy away from processes about which they think they have insufficient information (Frisch and Baron 1988). This happens in particular if an alternative process with a higher perceived informational content is available (Chow and Sarin 2001; Fox and Tversky 1995; Fox and Weber 2002). The effect appears to be particularly strong when somebody with a higher knowledge of the outcome generating process may serve as a comparison (Heath and Tversky 1991; Taylor 1995) or observes the decision (Chow and Sarin 2002). In Ellsberg's (1961) example the effect leads to preference for the urn with a known probability of winning, about which subjects feel more knowledgeable.

A preference for the more informative process may be explained by fear of negative evaluation, which is driven by the expectation that one's actions or judgments may be difficult to justify in front of others. When the audience's views on an issue are unknown and no prior commitment to one course of action exists, people have been found to make the decision which they deem most easily justifiable to others rather than the one that is intrinsically optimal (Shafir et al. 1993; Simonson 1989; Lerner and Tetlock 1999). In this way they minimize the risk of being judged negatively by others on their quality as decision makers.

Choosing the unfamiliar process entailed by the ambiguous urn may lead to embarrassment if a losing outcome should obtain (Ellsberg 1963; Fellner 1961; Heath and Tversky 1991; Roberts 1963; Tetlock 1991; Toda and Shuford 1965). The risky prospect is perceived as more justifiable than the ambiguous one because potentially available probabilistic information is missing from the ambiguous urn (Frisch and Baron 1988). This is consistent with people's preference for betting on future events rather than on past events, given that information about past events is potentially available whereas the future has yet to materialize (Brun and Teigen 1990; Rothbart and Snyder 1970). It is also consistent with people's unwillingness to act on the basis of ambiguous information (van Dijk and Zeelenberg 2003).

A decision based on more information is generally perceived as better (Tetlock and Boettger 1989), and it has been shown that a risky prospect is generally considered preferable to an ambiguous one by a majority of people (Keren and Gerritsen 1999). Kocher and Trautmann (2007) find that people correctly anticipate these negative attitudes towards ambiguity. If a bad outcome were to result from a prospect about which an agent had comparatively little knowledge, her failure may be blamed on her incompetence or 'uninformed' choice (Baron and Hershey 1988). A bad outcome resulting from a risky prospect, on the other hand, cannot be attributed to poor judgment. All possible information about the risky prospect was known, and a failure is simply bad luck (Heath and Tversky 1991; Toda and Shuford 1965). 
FNE is difficult to eliminate completely, because people naturally expect to make their choices in a social context. This may explain the pervasiveness of ambiguity aversion. Curley et al. (1986) found that letting more people observe the decision increased ambiguity aversion. To determine to what extent ambiguity aversion can exist beyond FNE, however, FNE should be completely eliminated. This will be achieved in our main experiment (Experiment 2). First, however, we present an experiment that replicates the findings of Curley et al. (1986) in a slightly different setup, and that shows that FNE also can arise with hypothetical choice.

\section{Experiment 1: Increasing other-evaluation}

Unless stated otherwise, tests will be one-sided in this paper because there usually is a clear direction of prediction with a one-sided alternative hypothesis. All results in this paper based on $t$-tests do not change if we use non-parametric Fisher tests instead. So as to be comparable to many traditional studies, and to illustrate the role of FNE there, we use hypothetical payoffs in this first experiment. We will make the ambiguous option more desirable so as to make indifferent subjects choose this option. Questionnaires with a simple Ellsberg choice task were distributed to 41 students in a classroom setting. The students were asked to make a simple choice between two hypothetical prospects. One, the risky prospect, gave them a 0.5 chance to win $€ 15$ and nothing otherwise. The second, the ambiguous prospect, gave them an ambiguous chance to win $€ 16$ and nothing otherwise. The higher outcome for the ambiguous prospect makes it more desirable than the risky prospect. The choice task was described as a classical Ellsberg two-color bet in which subjects could first choose the color on which they wanted to bet and then the urn from which they wanted to draw (instructions in the Appendix).

Nineteen subjects obtained instructions to write down their name and email address prior to taking the decision, with the explanation that they may be contacted by a member of the economics department and asked for explanations regarding their choice (high other-evaluation). Twenty-two subjects were not asked for any personal information before making their choice (low other-evaluation). Of the 19 subjects in the high other-evaluation condition, 15 chose the risky prospect (79\%). Of the 22 subjects in the low other-evaluation condition, 11 chose the risky prospect $(50 \%)$. The difference between the two treatments is significant $\left(t_{39}=-1.96, p=0.029\right)$.

In general, ambiguity aversion is high in both treatments, especially in view of the higher desirability of the ambiguous option. It should be noted that, even with hypothetical questionnaires and low other-evaluation, FNE is still not completely eliminated because people still imagine making a decision in a social situation (announce a color, draw a chip, receive a prize). Even imagined social encounters have been shown to be sufficient to induce embarrassment and FNE (Dahl et al. 2001; Miller and Leary 1992). In this framework, the thought of losing in front of others with the ambiguous urn may thus be enough to produce ambiguity aversion in hypothetical studies as well. Thus, in no experiment on ambiguity attitude in the literature known to us, could FNE be completely eliminated. In the next experiment we will completely eliminate FNE by explicitly making the subjects' preferences, and therefore the success of their decision, private information.

亚 Springer 


\section{Experiment 2 (Main experiment): Known versus unknown preferences}

\subsection{Experimental design}

Subjects $N=140$ subjects participated in individual sessions, 94 from the University of Amsterdam in The Netherlands and 46 from Erasmus University Rotterdam in The Netherlands. Most of these students studied economics or business.

Payoffs Subjects would always win one of two DVDs worth $€ 7$. They were not told the price of the DVDs. In two treatments subjects could earn up to $€ 0.80$ in addition to the DVD. All payoffs depended on subjects' choices and were paid for real.

The two DVDs were About a Boy and Catch Me if You Can. This pair was chosen in a preliminary survey among 50 students at the University of Maastricht because most students had a strong preference between them, but there was no difference in social desirability and no difference by gender, which made preferences unpredictable. On a scale from 3 (strongly prefer About a Boy) to -3 (strongly prefer Catch Me if You Can ), $70 \%$ of the subjects indicated a preference greater than or equal to 2 in absolute value. Twenty percent had a preference of 1 or -1 , and $10 \%$ were indifferent. The mean absolute preference was 1.74. Catch Me if You Can was slightly preferred overall (mean $=-0.82$ ).

Procedure We offered subjects a choice between a risky and an ambiguous prospect to win one of the two DVDs. A detailed description of the lottery mechanism is given later. We conducted four treatments that differed with respect to the experimenter's knowledge of the subjects' preference between the two DVDs and to whether there was a price difference between the risky and the ambiguous prospect (the ambiguous card was 50 cents cheaper). Table 1 shows the organization of the four treatments. It also indicates the total number of subjects in each treatment and in parentheses the number of students from Erasmus University Rotterdam.

Treatment KS replicates the classic Ellsberg (1961) example with known preference and a simple choice between the risky and the ambiguous prospect. At the beginning of the instructions the subjects were asked to decide which movie they wanted to win and to write down the name of the movie in front of the experimenter. Treatment US introduces unobserved preferences between the two prizes, which is the novelty of our design. It also requires a simple choice of the prospect. At the beginning of the instructions subjects were asked to decide which movie they wanted to win but not to tell the experimenter about their preference. The instructions are in the Appendix. The remainder of the instructions were identical for both treatments.

Table 1 Treatments

\begin{tabular}{lll}
\hline & Same price & Ambiguous card 50c Cheaper \\
\hline Known preference & Treatment KS $[N=40(21)]$ & Treatment KC $[N=30(2)]$ \\
Unknown preference & Treatment US $[N=40(20)]$ & Treatment UC $[\mathrm{N}=30(3)]$ \\
\hline
\end{tabular}

$K S$ Known preference with Same price (i.e., the cell in the second column and the second row); $K C$, $U S$, and $U C$ refer to the other cells. 
In Treatment $\mathrm{KC}$ we endowed subjects with $€ 10$ from which they had to buy either the risky prospect for $€ 9.70$ or the ambiguous prospect for $€ 9.20$, making the ambiguous choice 50 cents cheaper. They were allowed to keep the rest of the money. Preferences were known (same instructions as in Treatment KS). In Treatment UC the ambiguous prospect was again 50 cents cheaper (same instructions here as in Treatment KC) and preferences were unknown (same instructions here as in Treatment US). These two treatments were included to measure the economic significance of the ambiguity aversion, and to exclude the possibility that many subjects had been indifferent between all prospects and had chosen on the basis of minor psychological cues.

After deciding which DVD they wanted to win and writing it down or keeping the information to themselves depending on the treatment, subjects chose the prospect (paying for it in Treatments KC and UC) and played it at once. They immediately received the DVD they won. They always received one DVD. Then they filled out a background questionnaire and were dismissed.

The questionnaire contained demographic background questions, asked about the ex-post preferred movie (in Treatments US and UC with ex-ante unknown preference), and included some questions about the subject's perception of the game and the valuation difference between the two DVDs. The valuation difference was elicited as the subject's maximum willingness-to-pay to exchange her less preferred DVD for her more preferred DVD. It served again to verify that the subjects had clear preferences between the DVDs.

Lottery mechanism The lotteries were conducted as follows. First, the subjects assigned a symbol X to one DVD and a symbol $\mathrm{O}$ to the other at their own discretion. Then they chose to draw a card from one of two stacks, one representing the risky prospect and the other one the ambiguous prospect. Each stack consisted of about 50 cards. Each card had six numbers on its back, corresponding to the sides of a six-sided die. Next to each number there was either a symbol $\mathrm{X}$ or $\mathrm{O}$. In the risky prospect the subjects knew that there were exactly three Xs and three Os on the back of each card. In the ambiguous prospect they did not know the number of Xs and Os on cards, and they only knew that there were between zero and six Xs and a complementary number of Os on each card.

Within each stack, cards differed with respect to the actual location of the symbols over the six numbers, and the cards of the ambiguous prospect also differed in the number of Xs and Os. After having freely drawn a card from either the risky stack with exactly three Xs and three Os on each card, or from the ambiguous stack with an unknown composition of symbols, subjects observed the back of their card and threw a six-sided die to determine which DVD they had won. They always got one DVD.

The mechanism just described was chosen to make the process as transparent to the subjects as possible, and to make clear that the experimenter had no influence on the outcome of either prospect. The latter holds the more so as the subjects attached the two symbols to the two DVDs at their own discretion.

\subsection{Results}

In an experiment where both prizes are DVDs, indifference between the two outcomes of the prospect is possible and did occur for some subjects (details on the measurement of indifference are given in the Appendix). This section presents the 
results including all data. Excluding indifferences from the analysis does not qualitatively change the results (see Appendix).

Table 2 summarizes the results of the four treatments. It shows the percentage of subjects choosing the unambiguous prospect.

In Treatment KS significantly more than half of the subjects chose the risky prospect over the ambiguous prospect. We, thus, find ambiguity aversion, in agreement with common findings. Making preference private information in Treatment US eliminates ambiguity aversion. Here, we find that significantly less than half of the subjects chose the risky prospect. The difference in risky choices between Treatment KS and Treatment US is significant $\left(t_{78}=3.04, p=0.0016\right)$.

In Treatment $\mathrm{KC}$ subjects were, on average, indifferent between the risky prospect and the ambiguous prospect plus 50 cents. The number of subjects who chose the risky prospect is not significantly different from 50\%. In Treatment UC with a cheaper ambiguous card and unknown preference only $17 \%$ chose the risky prospect. The difference in risky choices between Treatment $\mathrm{KC}$ and Treatment UC is significant $\left(t_{58}=2.32, p=0.0121\right)$.

The average valuation difference between the two DVDs was $€ 2.19$. There was no significant effect of known versus unknown preference on valuation differences.

Running a probit regression of the effect of unknown preference and price difference on the probability that subjects choose the risky prospect shows that the effect of known versus unknown preference is highly significant (regression I in Table 3).

The marginal effect of a (discrete) change from known to unknown preference is an approximate 31 percentage-point reduction in the probability of choosing the risky card. The marginal effect of a 50 cents price reduction for the ambiguous card is an approximate 20 percentage-point reduction in the probability of choosing the risky card. Regressions II and III in Table 3 show that the size and the significance of the effect of unknown preference is stable if we control for gender, age and valuation difference. Valuation differences do not affect ambiguity attitude. Regressions IV and $\mathrm{V}$ show that the interaction of unknown preference and price and the interaction of indifference between the DVDs and price are insignificant.

Analyses of the questionnaire that the subjects filled out after the experiment corroborate our findings. Subjects in the unknown preference condition were asked ex-post about their preference between the two DVDs. Of those who had chosen the ambiguous prospect and were not indifferent between the DVDs, significantly more than half claimed to have won the DVD they preferred ( $p=0.04$, binomial test). No

Table 2 Percentage of risky choices

\begin{tabular}{llc}
\hline & Same price & Ambiguous Card 50c Cheaper \\
\hline Known preference & $\begin{array}{c}\text { Treatment KS } \\
65 \% \text { chose risky card }(>50 \%, p=0.04)\end{array}$ & $\begin{array}{c}\text { Treatment KC } \\
43 \% \text { chose risky card (not significant) } \\
\text { Unknown preference Treatment US }\end{array}$ \\
\begin{tabular}{ll}
$33 \%$ chose risky card $(<50 \%, p=0.019)$ & $17 \%$ chose risky card $(<50 \%, p=0.0002)$ \\
\hline
\end{tabular}
\end{tabular}

Tests are binomial.

$K S$ : Known preference with Same price; $K C, U S$, and $U C$ refer to the other cells. 
Table 3 Probit regression over all four treatments

\begin{tabular}{|c|c|c|c|c|c|}
\hline \multirow[t]{2}{*}{ Probit } & \multicolumn{5}{|c|}{ Dependent variable: choice of risky prospect } \\
\hline & I & II & III & IV & $\mathrm{V}$ \\
\hline Unknown & $\begin{array}{l}-0.3091 \\
\quad(0.0798)^{* *}\end{array}$ & $\begin{array}{l}-0.3204 \\
\quad(0.0806)^{* *}\end{array}$ & $\begin{array}{l}-0.3218 \\
\quad(0.0924) * *\end{array}$ & $\begin{array}{l}-0.3401 \\
\quad(0.1046)^{* *}\end{array}$ & $\begin{aligned} &-0.3160 \\
&(0.0808)^{* *}\end{aligned}$ \\
\hline Price & $\begin{array}{l}-0.2019 \\
(0.0832)^{*}\end{array}$ & $\begin{array}{l}-0.2077 \\
(0.084)^{*}\end{array}$ & $\begin{array}{l}-0.1548 \\
(0.1064)\end{array}$ & $\begin{array}{l}-0.23 \\
\quad(0.1131)^{*}\end{array}$ & $\begin{array}{l}-0.1899 \\
\quad(0.0871)^{*}\end{array}$ \\
\hline $\begin{array}{l}\text { Valuation difference } \\
\text { (ex-post) }\end{array}$ & & & $\begin{array}{l}0.0254 \\
(0.0215)\end{array}$ & & \\
\hline Unknown $\times$ price & & & & $\begin{array}{l}0.0531 \\
(0.184)\end{array}$ & \\
\hline Indifferent $\times$ price & & & & & $\begin{array}{l}-0.1861 \\
(0.2034)\end{array}$ \\
\hline Controls (gender, age) & & Yes & Yes & Yes & Yes \\
\hline Number of observations & 140 & 139 & 110 & 139 & 139 \\
\hline
\end{tabular}

The table reports marginal effects; standard errors in parentheses; $\times$ interaction; one subject did not indicate age; 15 subjects in Treatments $\mathrm{KC}$ and $\mathrm{UC}$ had no valuation question.

* Significant at the $5 \%$ level

** Significant at the $1 \%$ level, two-sided

such effect was found for those who had chosen the risky prospect. See part a) of Table 4.

Subjects in the unknown preference condition were also asked ex-post whether the experimenter could have correctly guessed which movie they preferred. Those who had chosen the risky prospect were significantly more likely to think that the experimenter could have guessed their preference than those who had chosen the ambiguous prospect $\left(t_{66}=-2.33, p=0.0115\right)$. See part $\left.b\right)$ of Table 4 .

Table 4 Analysis of ex-post questions

\begin{tabular}{|c|c|c|c|c|c|}
\hline \multirow[t]{3}{*}{ a) } & & \multicolumn{4}{|c|}{ Won movie } \\
\hline & & \multicolumn{2}{|c|}{ Ambiguous chosen } & \multicolumn{2}{|c|}{ Risky chosen } \\
\hline & & A & $\mathrm{C}$ & A & $\mathrm{C}$ \\
\hline Preferred & $\mathrm{A}$ & 13 & 5 & 4 & 2 \\
\hline Movie & $\mathrm{C}$ & 9 & 13 & 4 & 4 \\
\hline \multicolumn{6}{|c|}{ A: About a Boy; C: Catch Me if You Can. } \\
\hline \multicolumn{6}{|l|}{ b) } \\
\hline & & Ambiguous & Risky & & \\
\hline \multirow{2}{*}{$\begin{array}{l}\text { Think that experimenter could } \\
\text { guess preference }\end{array}$} & No & 47 & 12 & & \\
\hline & Yes & 4 & 5 & & \\
\hline
\end{tabular}

The numbers refer to numbers of subjects. 
3.3 Discussion of the experimental results of the main experiment

\subsubsection{The relevance of fear of negative evaluation}

The experimental results show that making preferences unknown to the experimenter leads to a 30 percentage-point reduction of ambiguity averse choices and makes ambiguity aversion disappear. In the current framework with valuation differences between the two prizes of about $€ 2.20$, this effect is stronger than the effect of making the ambiguous option 50 cents cheaper. This finding demonstrates that FNE has not only statistical but also economic significance.

In Treatment US we find a majority of subjects choosing the ambiguous option. With other-evaluation eliminated there may be no clear reason to choose either of the two stacks of cards and subjects may look for other minor psychological cues. Curiosity about the symbol distribution of the card of the ambiguous prospect or utility of gambling may lead to the preference for the ambiguous prospect. In Treatments $\mathrm{KC}$ and $\mathrm{UC}$, however, the price difference provides a clear cue for how to choose in the case of ambiguity neutrality. There is a significant effect of unknown preference in the comparison of these two treatments. Significantly more subjects were willing to incur the monetary cost to avoid the ambiguous prospect if preferences were known than if they were not known to the experimenter. In Treatment $\mathrm{KC}$ with known preferences, a considerable proportion of the subjects were ready to pay 50 cents, or about $23 \%$ of the average valuation difference, in order to use the risky prospect instead of the ambiguous one. In Treatment UC with unknown preferences the proportion of subjects ready to forego 50 cents for the risky prospect was considerably smaller.

The probit regression results show that the effect of making preferences private information is stable if we introduce other covariates. Including valuation differences, gender or age does not have an effect on the size or significance of the parameter for unknown preference.

Further evidence supporting the importance of FNE comes from the ex-post behavior of the subjects in the unknown preference condition. If they had chosen the ambiguous prospect, then they afterwards claimed that they were successful in winning their preferred DVD much more often than would be expected in a prospect with equal chances to win either DVD. This is not the case for those who had chosen the risky option. This finding suggests that losing after playing the ambiguous prospect is more embarrassing than after playing a 50-50 prospect. Kitayama et al. (2004) suggested that such ex-post justifications are motivated primarily by social evaluations. Such phenomena are known as cognitive bolstering in studies on the effects of accountability on decision making (Tetlock 1983). The ex-post behavior, therefore, further supports the FNE hypothesis.

We also find that subjects who had chosen the risky option were more likely to think that the experimenter could have guessed their preference. This indicates once more that there is a relation between ambiguity avoidance and the presumed possibility to be evaluated by others, again supporting FNE.

Given the overall evidence for the importance of known versus unknown preference in our experiment and the ex-post behavioral differences between subjects who chose the ambiguous and the risky prospect, FNE appears to be a major cause of ambiguity aversion, and in our experiment it even seems to be a necessary 
condition. We next discuss some alternative explanations and argue that they are less convincing as an explanation of the data than FNE.

\subsubsection{Alternative explanations}

Indifference It could be suggested that the subjects were mostly indifferent between prospects, and that majority choices resulted from minor psychological cues. This suggestion can be ruled out in our experiment because of the price differences between the Treatments KS and US versus KC and UC. In particular, indifference between the DVDs must imply a clear preference for the ambiguous prospect in the treatments where the latter is made cheaper.

It could be suggested that writing down the preferred DVD in Treatments KS and KC reinforced subjects' preference for that DVD. Then subjects in Treatments US and UC, who were not asked to write down their preference, might have had weaker preferences, closer to indifference. This could then have led to less ambiguity aversion. This suggestion can be ruled out for our experiment. First, we find that the valuation difference is not different for unknown or known preference, indicating no difference in strength of preference. Second, the insignificant effect of valuation differences in the probit indicates that there is no effect of strength of preference on ambiguity attitude. Also, inclusion of valuation differences does not affect the strong effect of unknown preference either in size or in significance. These results hold for both the data with and without indifferences.

Additional evidence against weaker preferences in the unknown preference treatments comes from the interaction between the preference and price manipulation (probit regression Table 3.IV). If subjects in the unknown preference conditions have weaker preferences between the DVDs than those in the known preference conditions, introducing the monetary incentive to choose the ambiguous prospect should have a stronger effect on choice in the unknown preference conditions. Subjects without a clear preference do not face a trade-off between ambiguity and money. The indifference explanation therefore predicts a negative effect of the interaction of 'unknown' and 'price' on the probability to choose the risky prospect in regression IV. We observe that the interaction effect is slightly positive and insignificant. As a control, including the interaction of indifferent subjects with 'price' in regression $\mathrm{V}$, we do find a negative effect on the probability of the risky choice as expected. However, owing to the small number of indifferent subjects the effect is not significant. We conclude that the indifference hypotheses cannot hold.

Fear of manipulation Fear of manipulation can be a reason for subjects to avoid the ambiguous prospect if they think the experimenter has an interest in reducing their probability of winning (Ellsberg 1961; Viscusi and Magat 1992; Zeckhauser 1986). Morris (1997) suggested that experimental subjects mistakenly apply strategic considerations appropriate in the real world and reduce their willingness to bet against the experimenter if probabilities are ambiguous. In footnote 24 he wrote: "It would be interesting to test how sensitive Ellsberg-paradox-type phenomena are to varying emphasis in the experimental designs on the experimenter's incentives." This paper presents such a test. In our experiment subjects knew they would always 
win a DVD, and there was no gain from manipulation for the experimenter. The lottery mechanism provided subjects with a choice of how to attach symbols to DVDs, and subjects always had to throw a die to determine the winning outcome. This made it very transparent that the experimenter had no interest and no possibility to influence the outcome.

Self-evaluation It might be argued that self-evaluation and anticipated cognitive dissonance or regret are the reason for the observed effect. In other words, the negative evaluation to be feared is not the evaluation by others but the evaluation by oneself. Self-evaluation was tested by Curley et al. (1986) and was found not to be significant. In our experiment self-evaluation should be the same in the known and the unknown preference treatments. The subject always knows whether she lost or won the prospect, and feedback was the same in all treatments. Hence, no difference between the treatments should then have been found. We conclude, therefore, that self-evaluation cannot account for our findings.

\section{Experiment 3: Ambiguity aversion and fear of negative evaluation as a personality trait}

The results presented so far suggest that FNE makes subjects shy away from the ambiguous option when a risky option is available. This interpretation implies that people who are more sensitive to negative evaluation by others (Leary 1983; Watson and Friend 1969) should show stronger ambiguity aversion. In order to test this assumption, we invited 63 subjects for a paid experiment. In the first part of the study subjects filled out an unrelated questionnaire on health insurance and food safety for which they were paid $€ 10$. At the end of the questionnaire we included Leary's (1983) 12-item FNE scale.

After completion of the questionnaire the subjects were given an Ellsberg twocolor choice task, which they would play for real money with the possibility of winning another $€ 15$ (instructions in the Appendix). This choice task was framed as a second, distinct experiment. Subjects were invited in groups of between four and six persons, and were told that their decisions would be read aloud by the experimenter and played out in front of the group. Subjects made a straight choice between the risky and the ambiguous option and gave their maximum willingnessto-pay (WTP; hypothetical) for both options.

Of the 63 subjects who took part in the experiment, 46 (73\%) chose the risky urn, resulting in high ambiguity aversion $(>50 \%, p=0.0002$, binomial test). The median of the Leary FNE score was 37 on a scale from 12 (low) to 60 (high), and Cronbach's alpha was 0.87 . The average WTP difference between the risky and the ambiguous urn (WTP risky option minus WTP ambiguous option) was €2.11.

A probit regression of choices on the FNE score and demographic controls gives an average marginal increase in the probability of an ambiguity averse choice of 1.1 percentage points per unit of the score, which is marginally significant $(p=0.076)$. A linear regression of the WTP difference on the FNE score and demographic controls gives an average increase of 7.3 cents per unit of the score $(p=0.026)$. 
Table 5 Median split

\begin{tabular}{lcccc}
\hline & $\begin{array}{l}\text { Number of } \\
\text { observations }\end{array}$ & $\begin{array}{l}\text { Average FNE score } \\
(\min 12, \max 60)\end{array}$ & $\begin{array}{l}\text { Average WTP } \\
\text { difference }\end{array}$ & $\begin{array}{l}\text { Percentage of ambiguity } \\
\text { averse choices (\%) }\end{array}$ \\
\hline Low FNE sensitivity & 31 & 29 & $€ 1.28$ & 67.7 \\
High FNE sensitivity & 32 & 41.97 & $€ 2.91$ & 78.1 \\
\hline
\end{tabular}

Table 5 illustrates the effect of the median split. The group that is more sensitive to negative evaluation with an average FNE score of 41.97 has an average WTP difference of $€ 2.91$. The less sensitive group with an average FNE score of 29 has an average WTP difference of $€ 1.28$. This difference is both statistically and economically significant for two prospects with an expected value of $€ 7.50\left(t_{61}=\right.$ $-3.04, p=0.0018$ ). The percentage of ambiguity averse choices is 10.4 percentage points higher in the high-FNE-sensitivity group, but this difference is not significant $\left(t_{61}=-0.92, p=0.1807\right)$.

For the low FNE group we observe a moderate but positive WTP difference and a majority of ambiguity averse choices. However, with a score of 29 this group is still far from being immune to other-evaluation, and they were facing the possibility of missing the $€ 15$ prize in front of a group of other students. We would therefore expect FNE to matter for this group as well in the experiment. Taken together the results show that people who are less sensitive to evaluation by others are less ambiguity averse. This finding supports the FNE hypothesis.

\section{Implications of FNE}

Empirically, the role of FNE has implications for economic phenomena that are affected by ambiguity aversion. A well-known example is the home bias in consumption and finance (French and Poterba 1991; Obstfeld and Rogoff 2000): people tend to invest and trade more in their own country than would be expected given the gains from international diversification. Transportation costs, capital controls, or other tangible institutional factors cannot explain the empirically observed size of the home bias. A number of authors have argued that the home bias can be explained by ambiguity aversion (Huang 2007; Kasa 2000; Kilka and Weber 2000; Uppal and Wang 2003). Geographically remote trade or investment opportunities are more unfamiliar to people and involve more ambiguity than local opportunities. People feel less knowledgeable about the more distant option.

FNE theory predicts different long-term stability of the bias in trade than in finance. Success or failure in trade will remain highly observable in the future, and the home bias in entrepreneurial decisions is therefore likely to be persistent. On the other hand, the propagation of technology generates a more anonymous and impersonal decision environment in finance (online brokerage, etc.). This is likely to reduce ambiguity aversion, and therefore the home bias, in the long run. The differential prediction for goods and equity markets is consistent with empirical evidence (Huang 2007; Tesar and Werner 1998). Additionally, we would expect that highly observable investments of otherwise large and sophisticated investors are more prone to home bias. Obstfeld and Rogoff (2000, p. 359) cite some evidence for this effect. 
In our experiments we manipulated other-evaluation in simple laboratory decision tasks. It would be interesting to study the effect in naturally occurring environments. Online brokerage provides such an environment because it offers investors more anonymity than a traditional human broker. Data on online investors suggest that they more heavily invest in growth stocks and high-tech companies than do investors with traditional brokerage accounts (Barber and Odean 2001, 2002). Such stocks are often associated with higher ambiguity in the finance literature. Konana and Balasubramanian (2005) find that many investors use both traditional and online brokerage accounts, and hold more speculative online portfolios. One of the investors they interviewed noted in the context of online trading (p. 518): "I don't have to explain why I want to buy the stock."

\section{Conclusion}

Fear of negative evaluation (FNE) has been proposed in the literature as a factor that increases ambiguity aversion. It was, however, not known to what extent ambiguity aversion can exist beyond FNE. We have introduced an experimental design in which preferences between outcomes are private information, so that others cannot judge the goodness of decisions and outcomes. Thus, we can completely control the presence or absence of FNE and investigate its role. In our experiment, ambiguity aversion completely disappears if FNE disappears. This shows that FNE is more important than has commonly been thought and that it may even be necessary for ambiguity aversion to arise.

Acknowledgement We thank Massimo Marinacci and Jacob Sagi for helpful suggestions. We also thank Kirsten Rohde for help with parts of the study conducted at the University of Maastricht.

Open Access This article is distributed under the terms of the Creative Commons Attribution Noncommercial License which permits any noncommercial use, distribution, and reproduction in any medium, provided the original author(s) and source are credited.

\section{Appendix}

\section{A1. Instructions experiment 1}

(Please report your NAME and EMAIL here:

A researcher from the Economics Department may contact you to ask for some explanations concerning your choice.)

Consider the following two hypothetical lottery options:

Option $A$ gives you a draw from a bag that contains exactly 40 poker chips. They are either red or green, in an unknown proportion. Before you draw, you choose one color. Then you draw. If the color you have chosen matches the color you draw you win $€ 16$. If the colors do not match, you get nothing.

Option $B$ gives you a draw from a bag that contains exactly 20 red and 20 green poker chips. Before you draw, you choose one color. Then you draw. If the color you 
have chosen matches the color you draw you win $€ 15$. If the colors do not match, you get nothing.

Imagine you had a choice between these two lottery options. Which one would you choose?

O Option A (bet on a color to win $€ 16$ from bag with unknown proportion of colors)

$\mathbf{O}$ Option B (bet on a color to win $€ 15$ from bag with 20 red and 20 green chips)

\section{A2. Instructions experiment 2}

In Treatments KS and US the instructions started with the following part:

In front of you there are two DVDs: About a Boy and Catch Me if You Can. Take your time to have a look at the boxes and then decide which one you would like to receive.

Write down the name of your preferred movie here:

Please also write down your name and movie preference in the list the experimenter will give to you.

In Treatments KC and UC this part was replaced by the following text:

In front of you there are two DVDs: About a Boy and Catch Me if You Can. Take your time to have a look at the boxes and then decide which one you would like to receive, but do not tell your preference to the experimenter.

In Treatments KS and US the first part was followed by the following text:

Next, the experimenter will give you two stickers, one with a cross on it, and one with a circle on it. Please attach one of these stickers to each of the DVDs as you like. The symbol (cross or circle) has nothing to do with your preference between the movies.

Then the experimenter will offer you a choice to draw a card from either of two stacks of cards: this card is used to determine which DVD you will win. This is done as follows:

On each card there are numbers 1 to 6 and either a cross or a circle next to each number (see example card). After drawing a card you will throw a six-sided die to determine the winning number and thereby the winning symbol: cross or circle. You obtain the DVD to which you attached the winning symbol before the game.

The two stacks of cards.

One stack of cards, called "50-50", contains cards that each have exactly three crosses and three circles on the back, randomly distributed over the six numbers of the die, e.g. 1: x, 2: 0, 3: 0, 4: x, 5: 0, 6: x.

The other stack of cards, called "?", contains cards that have an unknown number of crosses and circles on the back, but the sum of the number of the two symbols is equal to six again: that is, there are between zero and six crosses on the back, distributed randomly over the six numbers of the die, and a complementary number of circles, e.g. 1: x, 2:0, 3:0, 4: x, 5: 0,6:0.

Summary and timeline: you receive the two stickers $\rightarrow$ you attach the cross and circle sticker to the DVDs as you like $\rightarrow$ draw a card from the 50-50-stack or from the ?-stack $\rightarrow$ throw the die and observe which symbol wins $\rightarrow$ take the DVD to which you attached this symbol. End of the experiment.

Springer 
Please carefully consider all the information given to you about the chances of the two stacks of cards and your personal preferences between the DVDs, before making your choice between a draw from the 50-50-stack or the ?-stack of cards.

In Treatments $\mathrm{KC}$ and $\mathrm{UC}$ the first part was followed by the following text:

Next the experimenter will give you two stickers, one with a cross on it, and one with a circle on it. He will also give you $€ 10$ to be used during the game. Please attach each one of these stickers to each of the two DVDs as you like. The symbol (cross or circle) has nothing to do with your preference between the movies.

Then the experimenter will offer you a costly choice to draw a card from either of two stacks of cards (you have to choose one and can use the $€ 10$ to pay for it): this card is used to determine which DVD you will win. This is done as follows:

On each card there are numbers 1 to 6 and either a cross or a circle next to each number (see example card). After drawing a card you will throw a six-sided die to determine the winning number and thereby the winning symbol, cross or circle. You obtain the DVD to which you attached the winning symbol before the game.

The two stacks of cards.

One stack of cards, called "50-50", contains cards that each have exactly three crosses and three circles on the back, randomly distributed over the six numbers of the die, e.g. 1: x, 2:0, 3: 0, 4: x, 5: 0, 6: x. To draw a card from the 50-50-stack costs you $€ 9.70$ of your $€ 10$ endowment (the rest is yours).

The other stack of cards, called "?", contains cards that have an unknown number of crosses and circles on the back, but the sum of the number of the two symbols is equal to six again: that is, there are between zero and six crosses on the back, distributed randomly over the six numbers of the die, and a complementary number of circles, e.g. 1: x, 2: 0, 3: 0, 4: x, 5: 0, 6: 0 . To draw a card from the ?-stack costs you $€ 9.20$ of your $€ 10$ endowment (the rest is yours).

Summary and timeline: you receive two stickers and $€ 10 \rightarrow$ you attach the cross and circle sticker to the DVDs as you like $\rightarrow$ draw a card from the 50-50-stack for $€ 9.70$ or from the ?-stack for $€ 9.20$ and use the $€ 10$ to pay for it $\rightarrow$ throw the die and observe which symbol wins $\rightarrow$ take the DVD to which you attached this symbol. End of the experiment.

Please carefully consider all the information given to you about the chances and the prices of the two stacks of cards, and your personal preferences between the DVDs, before making your choice between a draw from the 50-50-stack or the ?stack of cards.

\section{A3. Results of experiment 2 if indifferences are excluded}

We defined a subject as indifferent if either her valuation difference was zero or she explicitly indicated that she was indifferent in the unknown preference condition. In Treatments $\mathrm{KS}$ and $\mathrm{KC}$ a subject could therefore be indifferent only if her valuation difference equals zero, while in Treatment US and UC either condition could apply. This leads to relatively more indifferences in the unknown preference treatments. We chose this measure of indifference to restrict the data to subjects with a clear preference and make sure we eliminated any possible bias owing to indifferences. 
Table 6 Percentage of risky choices without indifferences

\begin{tabular}{llc}
\hline & Same price & Ambiguous Card 50c Cheaper \\
\hline Known preference & Treatment KS $(N=36)$ & Treatment KC $(N=28)$ \\
& $69 \%$ chose risky card $(>50 \%, p=0.014)$ & $43 \%$ chose risky card (not significant) \\
Unknown preference & Treatment US $(N=29)$ & Treatment UC $(N=25)$ \\
& $31 \%$ chose risky card $(<50 \%, p=0.031)$ & $20 \%$ chose risky card $(<50 \%, p=0.002)$ \\
\end{tabular}

Tests are binomial.

$K S$ : Known preference with Same price; $K C, U S$, and $U C$ refer to the other cells

Table 6 summarizes the results of the four treatments. It shows the percentage of subjects choosing the unambiguous prospect.

Excluding indifferent subjects, the average valuation difference between the two DVDs was slightly higher at $€ 2.66$, and there was no significant effect of known versus unknown preference on valuation differences. Therefore, excluding indifferent subjects does not lead to any relevant changes in the probit results; see Table 7.

\section{A4. Instructions experiment 3}

On the table in front of you there are two bags. Each of them contains 40 poker chips which can be red or green. Bag one (white) contains exactly 20 red and 20 green poker chips. Bag two (beige) contains an unknown proportion of red and green chips.

First you will be called upon to make two choices. You will be asked to choose the bag from which you want to draw. You will also indicate the color on which you want to bet. You will indicate the choices on the decision sheet.

The other people participating in the experiment will make choices analogous to yours.

Second, when everybody has made his or her decisions and indicated them on the decision sheet, you will be invited to announce your decisions in front of the experimenter and the other people present, and to draw a chip from the bag you have chosen. If the chip you draw from the bag is of the color you have indicated, you will immediately be paid $€ 15$; if it is of the other color you receive nothing.

The order in which everybody announces his or her decisions and draws from his or her preferred bag will be randomly determined. Chips that are drawn will immediately be replaced in the bag such that the proportions do not change for the next person.

Table 7 Probit regression without indifferences

\begin{tabular}{llll}
\hline Probit & \multicolumn{4}{l}{ Dependent variable: choice of risky prospect } \\
\cline { 2 - 4 } & I & II & III \\
\hline Unknown & $-0.3232(0.0868)^{* *}$ & $-0.339(0.0873)^{* *}$ & $-0.3578(0.1003)^{* *}$ \\
Price & $-0.2094(0.0917)^{*}$ & $-0.2149(0.0931)^{*}$ & $-0.1512(0.1196)$ \\
Valuation difference (ex-post) & & & $0.0202(0.0239)$ \\
Controls (gender, age) & 118 & Yes & Yes \\
Number of observations & 117 & 90 \\
\hline
\end{tabular}

The table reports marginal effects; standard errors in parentheses.

* Significant at the $5 \%$ level

**Significant at the $1 \%$ level, two-sided

Springer 
After everybody has drawn from a bag, you will obtain the $€ 10$ from the first experiment, the $€ 15$ from the second experiment if you won it, and sign a receipt; then you can leave the room.

Please, no conversations during the experiment!

\section{Decision sheet}

Choice Task:

Please indicate the bag you want to draw from:

$\mathbf{O}$ bag 1 (20 red and 20 green chips) or $\mathbf{O}$ bag 2 (unknown proportion)

Please indicate the color that you bet you will draw from your chosen bag:

$\mathbf{O}$ red chip or $\mathbf{O}$ green chip

Additional hypothetical question:

Imagine you had to pay for the right to participate in a draw from the aforementioned bags with the possibility to win $€ 15$. How much would you pay for the right to participate in the prospects? Please indicate your valuations:

I would pay $€$ to participate in a draw from bag 1 (20 red and 20 green chips).

I would pay $€$ to participate in a draw from bag 2 (unknown proportion).

\section{References}

Barber, Brad M., and Terrence Odean. (2001). "The Internet and the Investor," Journal of Economic Perspectives 15(1), 41-54.

Barber, Brad M., and Terrence Odean. (2002). "Online Investors: Do the Slow Die First?" Review of Financial Studies 15(2), 455-487.

Baron, Jonathan, and John C. Hershey. (1988). "Outcome Bias in Decision Evaluation," Journal of Personality and Social Psychology 54(4), 569-579.

Becker, Selwyn, and Fred O. Brownson. (1964). "What Price Ambiguity? or the Role of Ambiguity in Decision Making," Journal of Political Economy 72(1), 62-73.

Brun, Wibecke, and Karl H. Teigen. (1990). "Prediction and Postdiction Preferences in Guessing," Journal of Behavioral Decision Making 3, 17-28.

Camerer, Colin F. and Martin Weber. (1992). "Recent Developments in Modeling Preferences: Uncertainty and Ambiguity," Journal of Risk and Uncertainty 5(4), 325-370.

Chesson, Harold W., and W. Kip Viscusi. (2003). "Commonalities in Time and Ambiguity Aversion for Long-Term Risks," Theory and Decision 54(1), 57-71.

Chow, Clare C., and Rakesh K. Sarin. (2001). "Comparative Ignorance and the Ellsberg Paradox," Journal of Risk and Uncertainty 22, 129-139.

Chow, Clare C., and Rakesh K. Sarin. (2002). "Known, Unknown, and Unknowable Unertainties," Theory and Decision 52, 127-138.

Curley, Shawn P., J. Frank Yates, and Richard A. Abrams. (1986). "Psychological Sources of Ambiguity Avoidance," Organizational Behavior and Human Decision Processes 38(2), 230-256.

Dahl, Darren W., Rajesh V. Manchanda, and Jennifer J. Argo. (2001). "Embarrassment in Consumer Purchase: The Roles of Social Presence and Purchase Familiarity," Journal of Consumer Research 28 (3), 473-481.

Ellsberg, Daniel. (1961). "Risk, Ambiguity and the Savage Axioms," Quarterly Journal of Economics 75 (4), 643-669.

Ellsberg, Daniel. (1963). "Risk, Ambiguity and the Savage Axioms: Reply," Quarterly Journal of Economics 77(2), 336-342.

Fellner, William. (1961). "Distortion of Subjective Probabilities as a Reaction to Uncertainty," Quarterly Journal of Economics 75(4), 670-689.

Fox, Craig R., and Amos Tversky. (1995). “Ambiguity Aversion and Comparative Ignorance," Quarterly Journal of Economics 110(3), 585-603. 
Fox, Craig R., and Amos Tversky. (1998). "A Belief-Based Account of Decision under Uncertainty," Management Science 44, 879-895.

Fox, Craig R., and Martin Weber. (2002). "Ambiguity Aversion, Comparative Ignorance, and Decision Context," Organizational Behavior and Human Decision Processes 88(1), 476-498.

French, Kenneth R., and James M. Poterba. (1991). "Investor Diversification and International Equity Markets," American Economic Review 81(2), 222-226.

Frisch, Deborah, and Jonathan Baron. (1988). "Ambiguity and Rationality," Journal of Behavioral Decision Making 1, 149-157.

Gilboa, Itzhak (ed). (2004). Uncertainty in Economic Theory: Essays in Honor of David Schmeidler's 65th Birthday. London: Routledge.

Heath, Chip, and Amos Tversky. (1991). "Preference and Belief: Ambiguity and Competence in Choice and Uncertainty," Journal of Risk and Uncertainty 4(1), 5-28.

Huang, Rocco R. (2007). "Distance and Trade: Disentangling Unfamiliarity Effects and Transport Cost Effects," European Economic Review 51(1), 161-181.

Kasa, Kenneth. (2000). "Knightian Uncertainty and Home Bias," FRBSF Economic Letter 2000-30, October 6.

Keren, Gideon, and Léonie E. M. Gerritsen. (1999). "On the Robustness and Possible Accounts of Ambiguity Aversion," Acta Psychologica 103, 149-172.

Kilka, Michael, and Martin Weber. (2000). "Home Bias in International Stock Return Expectation," Journal of Psychology and Financial Markets 1(3/4), 176-192.

Kitayama, Shinobu, Alana Conner Snibble, Hazel Rose Markus, and Tomoko Suzuki. (2004). "Is There Any 'Free' Choice," Psychological Science 15, 527-533.

Kocher, Martin G. and Stefan T. Trautmann. (2007). Selection and Markets for Risky and Ambiguous Prospects, Working paper, University of Rotterdam.

Konana, Prabhudev, and Sridhar Balasubramanian. (2005). "The Social-Economic-Psychological Model of Technology Adoption and Usage: An Application to Online Investing," Decision Support Systems 39(3), 505-524.

Leary, Mark R. (1983). "A Brief Version of the Fear of Negative Evaluation Scale," Personality and Social Psychology Bulletin 9(3), 371-375.

Lerner, Jennifer S., and Philip E. Tetlock. (1999). "Accounting for the Effects of Accountability," Psychological Bulletin 125, 255-275.

Miller, Rowland S., and Mark R. Leary. (1992). "Social Sources and Interactive Functions of Emotion: The Case of Embarrassment." In M. S. Clark (ed), Emotion and Social Behavior. Newbury Park, CA: Sage.

Morris, Stephen. (1997). "Risk, Uncertainty and Hidden Information," Theory and Decision 42(3), 235270.

Mukerji, Sujoy, and Jean-Marc Tallon. (2001). "Ambiguity Aversion and Incompleteness of Financial Markets," Review of Economic Studies 68(4), 883-904.

Obstfeld, Maurice, and Kenneth Rogoff. (2000). "The Six Major Puzzles in International Economics: Is There a Common Cause?" NBER Macroeconomics Annual 15(1), 339-390.

Roberts, Harry V. (1963). "Risk, Ambiguity and the Savage Axioms: Comment," Quarterly Journal of Economics 77(2), 327-336.

Rothbart, Mark, and Myron Snyder. (1970). "Confidence in the Prediction and Postdiction of an Uncertain Outcome," Canadian Journal of Behavioural Science 2(1), 38-43.

Sarin, Rakesh K., and Martin Weber. (1993). "Effects of Ambiguity in Market Experiments," Management Science 39, 602-615.

Savage, Leonard J. (1954). The Foundations of Statistics. New York: Wiley.

Shafir, Eldar, Itamar Simonson, and Amos Tversky. (1993). "Reason-based Choice," Cognition 49, 11-36.

Simonson, Itamar. (1989). "Choice Based on Reason: the Case of Attraction and Compromise Effect," The Journal of Consumer Research 16(2), 158-174.

Taylor, Kimberly A. (1995). "Testing Credit and Blame Attributions as Explanation for Choices under Ambiguity," Organizational Behavior and Human Decision Processes 64(2), 128-137.

Tesar, Linda L. and Ingrid M. Werner. (1998). "The Internationalization of Securities Markets since the 1987 Crash.” In R. E. Litan and A. M. Santomero (eds.), Brooking-Wharton Papers on Financial Services.

Tetlock, Philip E. (1983). "Accountability and Complexity of Thought," Journal of Personality and Social Psychology 45, 74-83.

Tetlock, Philip E. (1991). "An Alternative Metaphor in the Study of Judgment and Choice: People as Politicians," Theory and Psychology 1(4), 451-475. 
Tetlock, Philip E., and Richard Boettger. (1989). "Accountability: A Social Magnifier of the Dilution Effect," Journal of Personality and Social Psychology 57(3), 388-398.

Toda, Masanao, and Emir H. Shuford Jr. (1965). "Utility, Induced Utility, and Small Worlds," Behavioral Science 10(3), 238-254.

Uppal, Raman, and Tan Wang. (2003). "Model Misspecification and Underdiversification," Journal of Finance 58(6), 65-92.

Van Dijk, Eric, and Marcel Zeelenberg. (2003). "The Discounting of Ambiguous Information in Economic Decision Making," Journal of Behavioral Decision Making 16(5), 341-352.

Viscusi, W. Kip, and Wesley A. Magat. (1992). "Bayesian Decisions with Ambiguous Belief Aversion," Journal of Risk and Uncertainty 5(4), 371-387.

Watson, David, and Ronald Friend. (1969). "Measurement of Social-Evaluative Anxiety," Journal of Consulting and Clinical Psychology 33(4), 448-457.

Zeckhauser, Richard. (1986). "Comments: Behavioral versus Rational Economics: What You See Is What You Conquer,” Journal of Business 59(4), S435-S449. 